\title{
Representações de professores e gestores de uma escola que se diz pesquisadora
}

\author{
Amália Galvão Idelbrando, Ph.D. \\ Professora nas Faculdades \\ Metropolitanas Unidas-FMU, Brasil*
}

amaliagalvao58.ag@gmail.com

\section{Resumo (analítico)}

O presente texto é parte integrante dos resultados de uma pesquisa em Educação que se propõe a refletir tanto sobre as representações de professores e gestores de uma escola que se autointitula Escola Pesquisadora como também sobre a relação entre suas práticas e a construção de conhecimento de seus alunos. Os procedimentos metodológicos empreendidos foram: entrevistas semiestruturadas com 5 gestores, 8 professores e 10 alunos egressos, bem como análises documentais e observação participante. A perspectiva teórica que se buscou seguir foi a antropologia dialética, a partir da obra de Henri Lefebvre, para quem as representações se formam entre o vivido e o concebido de sujeitos determinados. O desdobramento das ações dessa escola inovadora proporcionou aos professores a ocupação de um lugar diferenciado: o de sujeitos de criação.

\section{Palabras-chave}

Pesquisa de escolas eficazes, envolvimento escolar, pesquisas escolares.

Thesauro

Eric-Educational Resources Information Center Thesaurus.

\section{Palavras-chave autor}

Escola pesquisadora, escola inovadora, pesquisa como princípio educativo, educação pela pesquisa.
Para citar este artículo

Galvão Idelbrando, A. (2019). Representações de professores e gestores de uma escola que se diz pesquisadora. Revista Latinoamericana de Ciencias Sociales, Niñez y Juventud, 17(2), 1-23. doi:10.11600/1692715x.17203

Historial

Recibido: 13.09.2018

Aceptado: 13.11.2018

Publicado: 26.04.2019

Información artículo

Este artigo de reflexão na área de Ciências da Educação, Educação Geral, faz uma síntese da investigação denominada «Escola pesquisadora? Representações de professores e gestores de uma escola que se diz pesquisadora: a relação entre suas práticas e a construção de conhecimento dos alunos». Pesquisa realizada entre fevereiro de 2013 e julho de 2017. 


\section{Representations of teachers and managers of a school which calls itself a school research}

Abstract (analytical)

This text is a part of the results of a research on Education aimed at reflecting not only on the representations of teachers and managers of a school which calls itself a Research School, but also on the relationship between its practices and the construction of its students' knowledge. The methodological pressures carried out were: semi-structured interviews with 5 managers, 8 teachers and 10 former students, as well as documentary analyses and participant observation. The theoretical perspective that we sought to follow was dialectical anthropology, based on the works of Henri Lefebvre, to whom the representations are formed between what is lived and what is conceived by certain individuals. The unfolding of this innovative school's actions provided the teachers with the opportunity to fill in a unique gap - the one of the subjects of creation.

Keywords

Effective schools research, school involvement, school surveys. Thesauro: Eric-Educational Resources Information Center Thesaurus.

Authors' keywords

Research school, innovative school, research as an educational principle, education through research.

\section{Representaciones de profesores y gestores de una escuela que se llama a sí mismo investigadora}

Resumen (analítico)

El texto es parte de los resultados de una investigación en Educación que se propone reflejar sobre las representaciones de profesores y gestores de una escuela que se llama a sí mismo Escuela Investigadora, así como sobre la relación entre sus prácticas y la construcción de conocimiento de sus alumnos. Los procedimientos metodológicos emprendidos fueron: entrevistas semiestructuradas con 5 gestores, 8 profesores y 10 alumnos egresados, análisis documentales y observación participante. La perspectiva teórica que se buscó seguir fue la antropología dialéctica, a partir de la obra de Henri Lefebvre, para quien las representaciones se forman entre lo vivido y lo concebido de sujetos determinados. El desdoblamiento de las acciones de esa escuela innovadora proporcionó a los profesores la ocupación de un lugar diferenciado: el de sujetos de creación.

Palabras clave Investigaciones de escuelas eficaces, participación escolar, investigaciones escolares. Thesauro: Tesauro de Eric-Educational Resources Information Center.

Palabras clave autores

Escuela investigadora, escuela innovadora, investigación como principio educativo, educación por la investigación.

\section{Información autora}

[*] Doutora em Educação pela Faculdade de Educação da Universidade de São Paulo-Feusp. Professora na PósGraduação das Faculdades Metropolitanas Unidas (FMU). Orcid: 0000-0001-7405-7286. Índice H5: 4. Correo electrónico: amaliagalvao58.ag@gmail.com 


\section{Introdução}

Este artigo, baseado em um estudo de um caso, tem por finalidade contribuir com a comunidade educativa ampla revelando a existência de uma escola na periferia da cidade de São Paulo com trabalho pedagógico focado na pesquisa como base para o ensino (Stenhouse, 2007) e a pesquisa como princípio educativo (Demo, 2011). Para tanto, foi realizada uma pesquisa empírica, qualitativa de forma a capturar as representações de educadores e gestores a fim de se estabelecer as relações entre as práticas pedagógicas e a construção do conhecimento dos educandos. Para a obtenção de nossos objetivos, foram realizadas, em acréscimo, pesquisas nos documentos produzidos pela escola: o Projeto Político Pedagógico (Escola Municipal de Ensino Fundamental Sebastiana da Silva, 2014), os trabalhos de conclusão de ciclo, o livro de artigos dos educadores, entre outros. As análises empreendidas que buscamos seguir foram na perspectiva da antropologia dialética da obra de Henri Lefebvre (1983, 2006), entre outros.

Mediante ao que foi exposto, e tendo em vista as diversas preocupações concernentes aos processos de ensino e aprendizagem, apresenta-se a pergunta que orientou a pesquisa que deu origem a este artigo, a saber: como professores e gestores de uma escola -que se autointitula pesquisadora- como representam ${ }^{1}$ a relação entre suas práticas e a construção do conhecimento que buscam desenvolver com seus educandos?

Stenhouse (2007) discute a pesquisa como base do processo de ensino e aprendizagem na escola básica bem como as barreiras erigidas que atrapalham o processo. Por sabermos que a postura investigativa não é um terreno fácil de se caminhar e tampouco uma maciça realidade na Educação como um todo, tal fato nos remete uma mirada próxima a fim de revelar quais são os entraves desse processo. O pensamento recrudescido de educação nos moldes tradicionais teme a pesquisa como procedimento pedagógico na

${ }_{1}^{1}$ Representações são entendidas aqui conforme o ponto de vista de Lefebvre (1983, p. 94), isto é, como fatos de palavras e de prática social. 
escola básica por entendê-la como divisão de poder junto aos educandos? É possível o ensino pela pesquisa na escola básica?

Sem dúvida, há entraves para o desenvolvimento da pesquisa como base para o processo de ensino e aprendizagem sob diversas variáveis e enraizados ao longo dos séculos. Stenhouse (2007) postula que ser um grande professor é ser um professor dialético. Nesse sentido, para ser um bom professor haveria a generosidade na divisão, junto aos alunos, de um conhecimento que o próprio professor muitas vezes poderia ainda não possuir, pois o ensino estaria baseado em problematizações, na pesquisa, ou pelo debate de ideias a partir das dúvidas. Stenhouse (2007) aponta que a «autoridade institucional» (p. 166) ainda se faz presente e se mantém como guardiã da verdade com um ensino baseado na autoridade. Mas a autoridade de quem?

O autor alude ao fato de que as comunidades escolares em grande medida executam o currículo baseados na instrução. Ou seja, não se trata do que ensinar, mas como ensinar, segundo ele «o uso educado e o uso inadequado da instrução» (Stenhouse, 2007, p. 164). Todavia, o autor adverte que é neste momento que encontramos os entraves psicológicos do ensino baseado na pesquisa: «ao ensinar existe sempre uma retenção de poder, ao mesmo tempo que uma transmissão de poder» (Stenhouse, 2007, p. 166).

Por fim, pesquisa como base do ensino é pouco reconhecida, pouco praticada, pois é muito trabalhosa e mais exigente do que a instrução por intermédio da exposição de conclusões e descobertas antigas, numa melhor hipótese.

Nesta mesma direção Pedro Demo (2011) articula a proposta da pesquisa como princípio educativo, ou seja, «a necessidade de fazer da pesquisa uma atitude cotidiana no professor e no aluno» (p. o7) como base da educação escolar. Esta pode e deve se valer de toda estrutura escolar existente e re-construir o processo de questionamento sistemático da realidade.

Esse movimento de uma pedagogia [pós] crítica entende que só se forma sujeitos num ambiente com sujeitos e só se conquista a liberdade e emancipação quando neste currículo os meios estão ajustados aos fins: a liberdade e a emancipação.

Desse modo, pensar em educação pela pesquisa, ou pesquisa como princípio educativo tem a ver com a aproximação da Educação e da pesquisa como seu método de formação com os sujeitos da escola, considerando que ambas estão contra a ignorância das massas, ambas apreciam o questionamento, pois a dúvida é sempre bem-vinda numa pesquisa, ambas abrangem teoria e prática e ambas se opõem a procedimentos manipu- 
lativos que possam negar a existência do sujeito histórico. A pesquisa como princípio educativo eleva a dúvida a parceira da construção do conhecimento, eleva a comunidade escolar a sentir a possibilidade do domínio de si mesma e, em particular, eleva os meninos e meninas investigadores a autoridade em seu processo educativo, em suas próprias vidas e auxilia a escola a se encontrar com a Educação.

Mediante isso, a Educação se inscreve num momento de educar para a democracia, ou seja, mais do que uma ideia, um conceito, uma lei ${ }^{2}$, deve efetivamente ser um modo de vida, um tipo de prática e estar no corpo dos educadores, em favor das aprendizagens das crianças e dos adolescentes.

Entretanto, o que ainda se percebe atualmente é a pouca mediação, poucas linguagens, e, de outro lado, muito conteúdo em uma ênfase bancária. Nessa perspectiva, urge realizar um questionamento acerca do processo de criação a partir da relação entre ensino e aprendizagem: os docentes seriam críticos e pesquisadores registrando suas práticas e refletindo sobre elas? Qual colaboração esse docente poderia prestar aos educandos do Ensino Básico de uma escola pública, com o objetivo de transformação atuante, crítica, de modo a garantir a aproximação, de fato, com a formação de um cidadão consciente, autônomo e participativo?

Dessa forma, remete-se ao ano de 2007, momento em que o Governo Federal brasileiro lançou o Programa Nacional Mais Educação, visando à promoção da educação integral no país.

Tal Programa foi instituído pela Portaria Interministerial n⿳⺈ 17/2007 e pelo Decreto Presidencial no $7083 / 2010$, que «integra e articula as ações do Plano de Desenvolvimento da Educação (PDE), como uma estratégia do Governo Federal para induzir a ampliação da jornada escolar e a organização curricular, na perspectiva da Educação Integral» (Brasil, 2007). A Educação Integral está, portanto, diretamente associada ao processo de escolarização de crianças, jovens e adolescentes, propondo a aprendizagem atrelada à vida, à cultura e aos interesses destes.

Esse Programa governamental teve como objetivo estimular o diálogo entre a escola e a comunidade, de forma a promover a ampliação dos espaços educativos e a aproximação da cultura dos educandos, valorizando a diversidade cultural brasileira.

${ }^{2}$ Lei nº 9394, de 20 de dezembro de 1996. Estabelece as diretrizes e base da educação nacional. Brasília, D. F., 1996. 
Nessa perspectiva, o Programa recomenda novas práticas e relações no ambiente da escola, de forma que,

O ideal da educação integral traduz a compreensão do direito de aprender como inerente ao direito à vida, à saúde, à liberdade, ao respeito, à dignidade e à convivência familiar e comunitária e como condição para o próprio desenvolvimento de uma sociedade Mais Educação republicana e democrática. Por meio da educação integral, se reconhece as múltiplas dimensões do ser humano e a peculiaridade do desenvolvimento de crianças, adolescentes e jovens. (Brasil, 2011, pp. 6-7).

Em consonância com o Programa Federal, o município de São Paulo organizou o Programa Mais Educação São Paulo (São Paulo, 2014), cujo objetivo pedagógico era contribuir para a melhoria da aprendizagem dos educandos. O Decreto nº $54.45^{2}$ (São Paulo, 2013) entre as determinações do programa está o Trabalho Colaborativo Autoral (TCA) voltado para alunos do $7^{\underline{O}}$ aos $9^{\underline{Q}}$ anos do Ensino Fundamental da rede pública de ensino, com o objetivo de fornecer ênfase ao desenvolvimento da construção do conhecimento, considerando o domínio das diferentes linguagens, a busca da resolução de problemas, a análise crítica e a estimulação dos educandos à autoria.

Em documento elaborado pela Secretaria Municipal de Educação de São Paulo (SME-SP), as ações estariam sustentadas por dois eixos, quais sejam: o primeiro, Currículo e Qualidade Social da Educação, A Unidade Educacional como Polo de Desenvolvimento Cultural e A unidade Educacional como Centro de Investigação Cognitiva; e o segundo, Gestão Pedagógica, Gestão Democrática e Gestão do Conhecimento. Este segundo eixo constitui o tema do presente artigo.

Como parte dessa proposta de reformulação, o Programa Mais Educação São Paulo reestruturou o Ensino Fundamental em outros ciclos; a ideia de ciclos teve como foco a aprendizagem, respeitando os tempos de aprendizado e de desenvolvimento das crianças e dos adolescentes.

Os ciclos compreendem o período de nove anos do Ensino Fundamental, sendo eles: o Ciclo de Alfabetização, do primeiro ao terceiro ano; o Ciclo Interdisciplinar, do quarto ao sexto ano; e o Ciclo Autoral, nos anos finais. Neste último, os educandos terão como objeto de estudo as áreas específicas, ou seja, todos os componentes curriculares, mas com a perspectiva de que, a partir do sétimo ano, orientados por seus professores, 
iniciem a construção de um projeto colaborativo autoral, denominado TCA (Trabalho Colaborativo de Autoria).

Independentemente desta proposta oficial, é possível identificar que ação similar já vinha sendo desenvolvida por uma escola da periferia da capital paulista. Em 2010, os educadores da referida unidade escolar, talvez como resposta aos efeitos de desgastes da educação tradicional, ousaram ao investir em novas práticas pedagógicas, e, em um primeiro momento, passaram a orientar os alunos dos últimos anos a realizar um trabalho de pesquisa como conclusão de curso. Essa postura de entendimento da pesquisa como um princípio educativo gerou uma ação por parte dos próprios educadores, a qual se concretizou com a elaboração de um livro (Ferreira, 2013) organizado em artigos, por meio dos quais os docentes procedem à reflexão de sua própria prática.

\section{Percurso Metodológico}

Assim, a relevância da pesquisa residiu em analisar uma escola autointitulada, desde 2010, como escola pesquisadora, tal como se pode confirmar no registro de trabalho de campo dos alunos nos Trabalhos de Conclusão de Curso (TCC). Fato interessante é observar que, em certa medida, a proposta da escola se aproximou daquela sugerida pela Secretaria Municipal da Educação de São Paulo. Essas proximidades constatadas levaram o grupo de educadores da escola a pensar que foram eles os precursores de uma ação que se tornaria Política Pública para a cidade de São Paulo a partir do final do ano de 2013, passando a ser uma exigência da política educacional da rede municipal. Portanto, a investigação proposta na pesquisa visou compreender o modo como se deu o processo, tanto da gênese quanto da produção de conhecimento, registro e reflexão de tais práticas por parte dos educadores.

Desta maneira, o pensamento foi arrazoar acerca da possibilidade de fomento à democratização para além do acesso e de permanência na escola, de modo que se possa verificar se estamos na contracorrente dos «excluídos do interior», conforme denunciado por Bourdieu (2010), ou se estamos, de fato, a construir a democratização do conhecimento.

Nesse contexto, o estudo de caso teve como objetivo geral compreender em que medida as representações dos professores e gestores de uma escola se relacionam com o avanço no desenvolvimento dos alunos segundo as finalidades da educação básica. 
Para o cumprimento dos objetivos propostos, foi realizada uma combinação de métodos e técnicas. Com vistas a uma análise de cunho qualitativo, para o estudo deste caso foram realizadas pesquisa bibliográfica, documental e de campo. Ademais, foram aplicadas entrevistas semiestruturadas e em profundidade análises dos dados e estudos comparativos do Projeto [Político] Pedagógico.

Por todo esse contexto, o estudo de caso se apresentou como a metodologia mais adequada para analisar a situação emergente. Ainda que as notas, avaliações escolares — como o Índice de Desenvolvimento da Educação Básica (Ideb) — entre outros dados estatísticos e informações numéricas que se tem à disposição, ajudem a mensurar os resultados das novas práticas, sendo parte fundamental desta análise, as questões centrais e a construção teórica e empírica do objeto de estudo exigem um tratamento qualitativo da investigação empreendida.

A fim de que as práticas relatadas como bem-sucedidas sejam percebidas como parte das intenções de uma escola autointitulada como pesquisadora, modelar e inovadora, é preciso considerar outros elementos do que apenas os resultados objetivos atingidos pelos novos fazeres e saberes; é necessário, portanto, considerar, sobretudo, as vivências dos sujeitos envolvidos na experiência com a construção do conhecimento em suas várias etapas, a saber: desde a elaboração das propostas, passando por sua aplicação, reformulação, documentação, e culminando na publicação das atividades, de seus resultados e também das reflexões acerca das práticas.

Assim, o estudo de caso justificou-se pela reunião «da especificidade e a particularidade complexas e em funcionamento» (Stake, 1989, p. 18), ou seja, pela necessidade de se compreender tanto as ações pedagógicas dessa unidade educacional, no âmbito de um sistema mais amplo, como a dinâmica deste grupo de profissionais de uma escola de Ensino Fundamental, sua articulação com o contexto educacional e com a conjuntura política e socioeconômica da cultura atual.

O caminho de pesquisa buscou seguir o método da antropologia dialética, orientação metodológica defendida por Henri Lefebvre, que desenvolveu uma teoria do conhecimento que se tornou base para análises teóricas e para o desenvolvimento metodológico de pesquisas que se empenham em investigar aspectos da realidade social concreta, por meio do método regressivo-progressivo, articulado à teoria das representações. 


\section{As contradições da escola na atualidade}

Analisar o desenvolvimento civilizatório frente à organização atual pressupõe a confluência das diferentes instituições existentes, incluindo-se a escola. Todavia, mudanças em instituições como a escola, ocorrem, em geral, com muito atraso se comparadas às transformações em outras áreas, tais como a tecnológica. Essa constatação se consubstancia como como uma dificuldade para os educadores em atender às necessidades de conhecimentos dos alunos.

Entender o significado dessas dificuldades no interior da escola é, com efeito, fundamental para os educadores. Mas, ao questioná-los sobre tal, é possível que fiquem reféns de algum aspecto tido como especial para eles. Possivelmente, os professores entenderão «as necessidades dos alunos» como sendo carências próprias de alunos especiais, ou mesmo ausência de políticas de atendimento, podendo tais necessidades serem também concernentes a aspectos objetivos materiais, ou afetividade, ou ainda, consumo dos conteúdos desenvolvidos pela escola, aqueles memorizados e reproduzidos. No entanto, uma porcentagem menor de educadores terá entendido essas necessidades, nos processos de ensino e aprendizagem, sob as dimensões do desenvolvimento pleno do cidadão, bem como da construção de ferramentas que serão imprescindíveis para as lutas sociais que os alunos enfrentarão, seja no presente, seja no futuro. Se a escola não entender este aspecto, as lutas continuarão como estão, desiguais.

Conforme assevera Hargreaves, Earl y Ryan (2001) «O ensino, bem como qualquer outra atividade humana, não é estático. O processo para moldar a próxima geração está evoluindo, acompanhando a sociedade como um todo» (p. 177). O entendimento implícito —ou seja, ações pedagógicas que permanecem recrudescidas - já não basta e também não se basta. $\mathrm{O}$ autor considera que as escolas necessitam de novos métodos pedagógicos, novos ambientes de aprendizagem e de desenvolvimento humano, a fim de que os adolescentes consigam responder às complexidades das exigências sociais que já efetivamente vivenciam ou as que os alcançarão (Hargreaves et al., 2001).

No entanto, John Dewey (2011), há muito, já havia aberto essa trilha como um caminho acrescentando ainda que não é o abandono ou a rejeição das práticas tradicionais a fórmula adequada para se construir uma nova Educação. Dewey (2011) aponta na direção da experiência, não de qualquer experiência, muito menos as deseducativas, como aquelas resultantes de exercícios automáticos que eliminam a curiosidade das meninas e me- 
ninos ou das repetições de regras e fórmulas que em nada colaboram com os desafios na realidade da vida delas e deles. Dewey (2011) argumenta sobre a experiência educativa e do princípio da teoria como filosofia da Educação, aquela que tem uma função orgânica, amadurecida na gênese do verbo, da linguagem, de um plano de intenções, de ideias e do simbólico.

Segundo Dewey (2011), «assim como nenhum homem vive e morre para si mesmo, nenhuma experiência vive e morre para si mesma» (p. 28), ou seja, cada experiência vivida é o degrau que sustentará o movimento e os sentidos dos próximos passos para os aprendizados futuros, para as pesquisas futuras, para as perguntas infindas ou as experiências que conectam os sujeitos às novas e fundantes experiências. Em Educação é necessário pensar o impensável e o impensável só insurge no âmago do próprio pensamento em movimento que nasce da reflexão da própria experiência.

De nada adianta falar em experiência se não partirmos de um pensamento reflexivo, é ele que garante as feições da experiência construída junto ao que foi partilhado entre estudantes e professor, por isso, «refletir é olhar para o que aconteceu a fim de extrair a rede de significados que constitui o principal material para um comportamento inteligente em experiências futuras -é o coração da organização intelectual e da mente disciplinada» (Dewey, 2011, p. 91).

Para Dewey (2010), a reflexão e a experiência caminham juntas, a reflexão ilumina a elaboração dos sujeitos frente ao como era antes da experiência e marca o que veio ou como ficou depois dela, uma imbricada na outra, como flores e sementes juntas para anunciar de onde se veio e para onde se foi. Por isso em Educação desejamos tanto a chegada dos frutos pois é sob essa perspectiva em que percebemos o fluxo tão caracterizado na composição da experiência, não há conexões mecânicas, apenas pura continuidade, conforme cita Dewey (2010),

Em uma experiência, o fluxo vai de algo para algo. À medida que uma parte leva a outra e que uma parte dá continuidade ao que veio antes, cada uma ganha distinção em si. $\mathrm{O}$ todo duradouro se diversifica em fases sucessivas que são ênfase de suas cores variadas. Por causa da fusão contínua, não há buracos, junções mecânicas nem centros mortos quando temos uma experiência singular (p. 111).

Sendo assim, algumas percepções se materializam, a fim de empoderar o processo investigativo de modo que o professor condutor possa contribuir para que os estudantes 
consigam caracterizar as fases dos estudos e que a reflexão daquilo que se investiga em processo pedagógico possa se configurar como uma experiência.

Fullan (2009) adensando as reflexões refere-se à qualidade das experiências mencionadas por Dewey (2011) afirmando que «as pessoas não aprendem fazendo, mas pensando sobre o que estão fazendo» (p. 48).

No entanto, a escola, ao não utilizar a pesquisa sistematicamente como princípio educativo, influi em aspectos da dimensão política, tal como a relação da escola com a comunidade e o atendimento da função social da escola, em especial, a aprendizagem.

Decerto que educadores, em alguma medida, apreendem a complexa e quase inflexível realidade da estrutura centralizadora da escola, bem como o tipo de [não] participação que possuem: são pouco ouvidos, pouco considerados, são tratados como engrenagens de «uma máquina de ensinar» (Canário, 2005, p. 78) conteúdo consumido por clientes adaptados ao consumo deste.

A organização da estrutura burocrática das instituições escolares é passível de outra estruturação por parte dos grupos que se formam entre os adultos, de forma a se esquivar de sua lógica ditada pelo Poder Público, as crianças e adolescentes, por exemplo, também criam suas próprias formas de agrupamentos de modo que, conscientemente, transgridam a vigilância imposta pelos adultos.

Como instância de organização racional e normativa, as escolas atuam não só como uma máquina de ensinar, mas também de vigiar, de hierarquizar, de recompensar e, por sua arquitetura, também de isolar o professor em salas de aulas (Foucault, 1977, 2003).

O distanciamento da Educação no que concerne às práticas da investigação fortalece a lógica focada mais no ensino e menos na aprendizagem, isto é, mais na adaptação e na disciplina do aluno, promovendo um ensino mecânico de memorização de conteúdos enciclopedistas, intelectualistas, celetistas, classificatórios e seletivos, ou seja, com menos investimento na formação do sujeito pleno. Nessa direção, considera o docente como o sujeito central da educação e, os discentes, como receptáculos dos saberes acumulados pela humanidade.

No entanto, apesar das denúncias, esta organização da escola continua com força na atualidade, com arcaísmos tidos como necessários aos procedimentos educativos; ou seja, permanece presente nos meios escolares da educação pública e privada, e, muitas vezes, é vista como única possibilidade. Concorda-se com o ponto de vista externado por Hargreaves et al. (2001, p. 177) quando este diz que «mudanças de padrões de agrupamento, 
organização da escola ou resultados de currículo dificilmente terá qualquer impacto positivo de destaque em sala de aula ou nos alunos, a menos que também haja mudanças no modo como os professores ensinam».

Entretanto, a pesquisa como base do ensino (Stenhouse, 2007) e a pesquisa como princípio educativo (Demo, 2011) buscam considerar educadores e educandos, como sujeitos do processo de construção do conhecimento, relacionando um ao outro com envolvimento de empatia, de alteridade, de afetividade, de mediação e de construção de conhecimento.

Entre o hiato criado pelo distanciamento da Educação nos moldes liberais e a Educação pela pesquisa houve a expansão do atendimento aos alunos — fato que é louvável一, mas tal acesso à escola ocorreu sem serem proporcionadas as devidas condições de trabalho para os professores e para o efetivo atendimento aos alunos. A qualidade de formação dos professores ainda é questionável (sem proceder-se aqui à culpabilização da vítima); a gestão, apesar da leỉ , ainda é, em sua essência, autoritária, e os efeitos desse conjunto atinge diretamente as alunas e alunos, pondo em risco o atendimento às reais necessidades deles. Isso significa tornar as discussões ainda mais evidentes, problematizando o seguinte ponto: os educandos efetivamente se utilizam, em suas vivências cotidianas e na produção da própria realidade, do conhecimento que a escola lhes propõe? As jovens e os jovens entendem o significado dos conteúdos que aprendem, de forma a utilizá-los no cotidiano de suas vidas? A escola como organização atrai, seduz e incentiva os educandos à permanência nos estudos? A autoras Rocha y Rozek (2018), salientam que «é preciso que a escola encontre formas para que as aprendizagens formais tenham significado para as pessoas, de acordo com suas trajetórias de vida e suas necessidades» (p. 367). Os «significados» a que as autoras se referem, ou os sentidos, é a aproximação do discurso da escola organizada com a realidade vivida pelas meninas e meninos das escolas.

As considerações acerca das indagações feitas têm ampla complexidade, no entanto, o que salta aos olhos é o fato de que os professores, em grande medida, não conseguem efetiva articulação entre seus pares para alguma organização de transformação e mudança, e, quando isto ocorre, é em um movimento solitário que acaba por incomodar a lógica sob a qual a escola está organizada; por conseguinte, não sobrevivem sem apoio institucional. São estas tensões, dentre outras, que os professores vivenciam cotidianamente,

3 Lei nº 9394, de 20 de dezembro de 1996. Estabelece as diretrizes e base da educação nacional. Brasília, D. F., 1996. Art. VIII - gestão democrática do ensino público, na forma desta Lei e da legislação dos sistemas de ensino. 
são elas que podem deixá-los na defensiva, de modo que os conteúdos de suas ponderações (reflexões) invariavelmente fiquem prejudicados. Os docentes estão tão próximos a toda sorte de dificuldades e urgências junto às meninas e meninos e, simultaneamente, tão longe das instâncias administrativas no modelo hierárquico de cima para baixo e de fora para dentro, sempre submetidos àqueles que pensam as políticas pedagógicas sem que os educadores sejam considerados como parceiros das investigações educacionais. Assim, estes professores refugiam-se em grupos de afinidades, não raro, esses grupos são de muita lástima e pouco estudo, em virtude da sobrecarga de horários, do grande número de turmas e, basicamente, da estrutura da escola (Hargreaves et al., 2001).

Por fim, é necessário abordar uma questão de enorme importância: a quem incomoda a mudança educacional em seus modos fundamentais? Transformar a Educação na direção de torná-la redistributiva do poder e da cultura é um ato político e, é exatamente nessa dimensão - a política- que se encontram as maiores resistências a serem enfrentadas. Hargreaves et al. (2001) esclarece que «A educação é a maior guardiã da oportunidade e um distribuidor poderoso de chances na vida» (p. 206).

Dialoga-se aqui no que tange à esfera da educação pública, isto é, o cenário apresenta terrenos pantanosos, mas não só: existem, com efeito, oásis de terra firme se multiplicando. As formações dos grupos no interior da escola escapam às estruturas pensadas pelos legisladores, o que a torna estas instituições diferentes das demais escolas, todas públicas; são diferenciadas em seus agrupamentos como recursos humanos, de interesses, afinidades e propósitos.

\section{A escola, o bairro e seus documentos}

O prédio da escola é amplo com dois andares pátio de recreação, quadra de esportes, sala de leitura, sala de vídeos, laboratório de informática educativa. As salas de aulas são limpas, arejadas, com cortinas tudo bem cuidado esteticamente. Entretanto, uma escola tem seu prédio como um equipamento, pois uma escola, de verdade, acima de qualquer coisa é o encontro de pessoas.

A escola analisada na pesquisa que teve seu início como uma fazenda com plantação de juta. O proprietário faleceu e, por conseguinte, a fazenda ficou abandonada, tornando-se terras improdutivas; o governo, então, desapropriou-a devido aos muitos impostos 
não pagos. Nesse meio tempo, muitas famílias, advindas de várias regiões, inclusive da região nordeste, foram ocupando a área.

Várias tentativas de reintegração de posse ocorreram atendendo a diversas ordens judiciais impetradas pelo governo estadual e, por intermédio de intervenções policiais, as famílias, apesar de inicialmente tentarem resistir, acabaram por serem retiradas do local.

Em 1989, especificamente em um dos episódios das tentativas de ocupação, por volta de cinco mil pessoas fizeram um círculo de mãos dadas; na linha de frente, os homens e algumas mulheres, na esperança de tentarem dialogar com os representantes do governo e da polícia repressora que intentavam a reintegração; na linha mediana, mulheres e crianças, combinando-se para uma fuga estratégica, caso a situação se complicasse. As negociações não foram bem-sucedidas e o conflito continuou. Entretanto, a organização política das famílias, que não arredaram pé em resguardar o direito à moradia, fez a diferença na vida deles e fez a resistência necessária aos ataques governamentais de expulsão destes daquele local. Por fim, em 1990, deu-se a efetiva ocupação.

As famílias foram cadastradas atendendo aos quesitos de cessão. Foi constituída uma associação para realizar reivindicações e decisões coletivas. Conseguiram erguer as construções, feitas em regime de mutirão e com a conscientização dos direitos e deveres de cidadania. Antes mesmo de começarem as construções, houve um planejamento que destinava áreas para se erigir escolas, creches, bem como reservadas ao lazer e a um centro cultural (Projeto Político-Pedagógico).

\section{O Projeto Político-Pedagógico}

Como análise documental da unidade escolar pesquisada, neste tópico são apresentados: um cotejamento entre o Projeto Pedagógico (PP) (Escola Municipal de Ensino Fundamental Guiseppe Tavolaro, 2009) (antes da realização do TCC pelos alunos e do livro pelos professores) e o Projeto Político-Pedagógico (PPP) de 2014; o livro de artigos escritos pelos educadores; os Trabalhos de Conclusão de Ciclo (TCC) pelos alunos dos oitavos anos; e, por fim, os resultados do Índice de Desenvolvimento da Educação Básica (Ibeb).

Para melhor visualização desta análise, foram sistematizados dois quadros enfatizando as principais aproximações entre os projetos dos anos de 2009 e de 2014, bem como vários distanciamentos, tais como são demonstrados no Quadro 1 e no Quadro 2. 


\section{Quadro 1}

Aproximações entre os Projetos de 2009 e de 2014

\begin{tabular}{ll}
\hline \multicolumn{1}{c}{2009} & 2014 \\
\hline Projeto Pedagógico & Projeto Político-Pedagógico \\
Investimento em alfabetização & Investimento em alfabetização \\
Preocupação com a construção da cidadania & Preocupação com a construção da cidadania \\
\hline
\end{tabular}

Nota. Fonte: Projeto Pedagógico (2009); Projeto Político-Pedagógico (2014).

\section{Quadro 2}

Distanciamentos entre os Projetos de 2009 e de 2014

\begin{tabular}{|c|c|}
\hline 2009 & 2014 \\
\hline Projeto Pedagógico & Projeto Político-Pedagógico \\
\hline Nomenclatura do Projeto-PP & Nomenclatura do Projeto-PPP \\
\hline Dois ciclos, com retenção nos anos finais & $\begin{array}{l}\text { Três ciclos, com retenção ao final do primeiro e em } \\
\text { todos os anos do terceiro }\end{array}$ \\
\hline $\begin{array}{l}\text { Aparentemente, apenas seguia as orientações da } \\
\text { Secretaria Municipal de Educação }\end{array}$ & A escola autodenomina-se pesquisadora \\
\hline $\begin{array}{l}\text { Não há referências sobre os temas abordados na } \\
\text { formação continuada }\end{array}$ & Formação continuada voltada para a pesquisa \\
\hline $\begin{array}{l}\text { Resultados das avaliações expressos em concei- } \\
\text { tos (NS, S e P) }\end{array}$ & $\begin{array}{l}\text { Resultados das avaliações expressos em conceitos no } \\
\text { ciclo de Alfabetização (NS, S e P) e, nos demais, em } \\
\text { notas ( } 0 \text { a 10) }\end{array}$ \\
\hline Projeto Especial de Ação-PEA & Projeto Especial de Ação-PEA \\
\hline Alfabetização & Escola Pesquisadora \\
\hline $\begin{array}{l}\text { Alunos não apresentavam Trabalho de Conclusão } \\
\text { de Curso }\end{array}$ & $\begin{array}{l}\text { Consolidação dos Trabalho Colaborativo de Autoria- } \\
\text { TCAs, por intermédio da Portaria SME n 5.930/13 }\end{array}$ \\
\hline
\end{tabular}

Nota. Fonte: Projeto Pedagógico (2009); Projeto Político-Pedagógico (2014).

Em políticas educacionais de algumas gestões de governos que compreendiam o elemento político como subjacente ao pedagógico, ou seja, verdadeiramente um Projeto Político-Pedagógico, nestas se «atribui à escola a construção de um projeto de escola capaz de the auferir maior nitidez político-pedagógica para as várias ações que desenvolve no cumprimento das funções atribuídas socialmente à escola» (Caria, 2010, p. 97). No 
projeto de 2009, a palavra «político» não é visível como nomenclatura talvez pelo entendimento de que já se encontre implícita. Contudo, em 2014, o projeto da escola teve o «político» efetivamente revelado.

Pode-se perceber que antes e depois da transição da escola que se define como pesquisadora a preocupação em relação à alfabetização foi mantida como um dos pilares do projeto; o PEA foi readequado visando atender à escola pesquisadora como formação continuada dos educadores.

\section{O livro elaborado: reflexões dos educadores}

O livro intitulado Escola Pesquisadora: uma possibilidade de formação se apresentou como parte de um projeto que reuniu dezoito artigos de professores de uma unidade educacional pública municipal com a finalidade de refletir acerca da própria prática, mantendo-se fiel à natureza do trabalho. Neste contexto, em alguma medida, esses educadores saíram do lugar de tutela por políticas públicas oriundas da ordem de cima para baixo e ousaram na produção de conhecimento situando o próprio local de trabalho como local de produção de conhecimento e reflexão. Embora seis artigos tivessem um tom prescritivo, todos eles estiveram alinhados à proposta de escola pesquisadora è̀ pesquisa como princípio educativo em nível da escola básica.

Esses educadores, sob a perspectiva da escola pesquisadora (Stenhouse,2007; Demo, 2011), dialogaram com elementos e com momentos indicadores da gênese de uma obra: o saber, a técnica, o desejo, o trabalho, o lúdico, a seriedade, o social, o utópico, as representações, a forma, a presença e a ausência se entrecruzando, consolidando-se ou se superando, dialeticamente, nas condições e circunstâncias de uma escola pública. Essa reunião de elementos e de momentos pode(ria) ter se antecipado às Políticas da Secretaria Municipal de Educação de São Paulo (SME), e, em seu desenvolvimento, como genealogia, ter dado as condições do despertar de uma Obra (Lefebvre, 2006).

\section{Os Trabalhos de Conclusão de Ciclo}

São apresentados, no Quadro 3, alguns títulos dos trabalhos de TCCs entre os anos de 2010 a 2014 . 
Quadro 3

Trabalhos de Conclusão de Ciclo entre 2010-2014

\begin{tabular}{|c|c|c|}
\hline Matemática & $\begin{array}{l}\text { As dificuldades de se aprender matemática } \\
\text { Geometria na natureza }\end{array}$ & 2010 \\
\hline \multirow{4}{*}{ Inglês } & A influência do Hip Hop na juventude brasileira & \\
\hline & Países que utilizam o inglês como o segundo idioma & 2010 \\
\hline & A influência de jogos de videogame na aprendizagem de língua & \\
\hline & inglesa & 2013 \\
\hline \multirow{4}{*}{ Língua Portuguesa } & A importância da leitura na formação do cidadão* & \\
\hline & Música: importante veículo de comunicação & 2012 \\
\hline & Publicidade & 2013 \\
\hline & As crônicas de Walcyr Carrasco & 2010 \\
\hline \multirow{2}{*}{ História } & Comunismo no Brasil & 2011 \\
\hline & Cultura de Massa & 2013 \\
\hline Arte & História da dança & 2013 \\
\hline Educação Física & Atividade física na melhor idade* & 2013 \\
\hline
\end{tabular}

Nota. *Foco das observações da pesquisa.

Observa-se que as disciplinas de Língua Inglesa, Língua Portuguesa e História e relacionaram seus conteúdos às vivências dos alunos ao abordarem temas atuais como Hip Hop, jogos de vídeo game, música e cultura de massa, entre outros. No entanto, em Educação Física houve o relacionamento das educandas autoras com um processo de construção de alteridade no momento que elas deslocaram seus olhares de vida juvenil às necessidades das pessoas em um momento de vida que requererem outros cuidados.

\section{O Índice de Desenvolvimento da Educação Básica (Ideb)}

Em relação ao Índice de Desenvolvimento da Educação Básica (Ideb), em 2014, foram divulgados pelo Instituto Nacional de Estudos e Pesquisa (Inep) os dados referentes às escolas brasileiras. O Quadro 4 e o Quadro 5 mostram os resultados da Emef4 pesquisada:

4 Emef significa Escola Municipal de Ensino Fundamental. 
Quadro 4

Ideb verificado - $4^{\underline{a}}$ séries $/ 5^{0}$ anos

\begin{tabular}{ccc}
\hline & Ideb observado & Metas projetadas \\
\hline 2005 & 4.1 & \\
2007 & 4.5 & 4.1 \\
2009 & 5 & 4.5 \\
2011 & 5.4 & 4.9 \\
2013 & & 5.2 \\
2015 & 5.8 & 5.4 \\
\hline
\end{tabular}

Quadro 5

Ideb verificado-8 ${ }^{\underline{a}}$ série/ $9^{-0}$ ano

\begin{tabular}{ccc}
\hline & Ideb observado & Metas projetadas \\
\hline 2005 & 3.8 & \\
2007 & 3.8 & 3.8 \\
2009 & 4.3 & 4 \\
2011 & 4.9 & 4.2 \\
2013 & 4.8 & 4.6 \\
2015 & & 5.0 \\
\hline
\end{tabular}

Sintetizando, o Ideb 2015 nos anos iniciais da rede municipal já atingiu a meta, mas teve queda e não alcançou 6,o. Há o desafio de buscar garantir mais alunos aprendendo e com um adequado fluxo escolar. Já nos anos finais da rede municipal, o Ideb 2015 atingiu a meta e cresceu, contudo, não alcançou 6,o. Observa-se o índice acima daquele projetado para o Fundamental I, em 2007, e, no Fundamental II, o índice acima do projetado também em 2007; logo, a escola se encontrava em um processo virtuoso no que se refere à relação ensino e aprendizagem.

Os usuários da referida Emef possuem de histórico de lutas sociais por garantia de seus direitos de moradia, bem como também de assistência pelas diferentes instituições. Foi possivel presenciar, em uma reunião de conselho de escola, a participação de um senhor, um líder comunitário, fator que levou a pesquisadora a pensar que ele seria, dentre 
outros pais da comunidade, uma forte representação e também uma figura mediadora entre a escola e a comunidade. Naquela região, berço de lutas populares travadas contra o Estado, também haveria o gérmen da transformação. A retomada da história da região e o relato do que se presenciou na escola na atualidade permitem descrevê-la na horizontalidade da vida social. Essa descrição (momento descritivo do método dialético, tal como denomina Lefebvre) possibilitou uma análise em que se identifica o que pode ser chamado de gérmen de uma prática de transformação da população local.

Em relação aos resultados do Ideb, desde 2005 a unidade escolar já apresentava superação no que concerne às metas estabelecidas. De certo, as ações da escola, de algum modo, estiveram ordenadas e coordenadas para essas finalidades antes mesmo da mudança do ensino com a pesquisa como princípio educativo. Uma assertiva de Lefebvre (2006, p. 297) pode ajudar a pensar este episódio: «não há acaso e nem determinismo que fique submisso à vontade». Aquela equipe de educadores já perseguia uma mudança cultural da escola.

\section{Considerações finais}

Para nós, educadores, a realidade mal-afamada ou os ataques às escolas parece ser um assunto saturado. Parece existir uma crença de que as instituições escolares estão enquadradas sob uma organização imutável, mas não.

Por força da Lei de Diretrizes e Bases da Educação Nacional _LDB nº 9394 (Brasil, 1996) quando esta dispõe, em seu Art. 14, incisos I e II: «Os sistemas de ensino definirão as normas da gestão democrática do ensino público na educação básica, de acordo com as suas peculiaridades e conforme os seguintes princípios: participação das comunidades escolares ou equivalentes»-, as escolas, aparentemente, seguem essa orientação se pautando na obrigatoriedade do cumprimento dessa Lei, provavelmente sem refletirem e discutirem amplamente o real significado de democracia, conforme nos alude Dewey (2011), é muito limitante pensar em democracia apenas como uma forma de governo distante dos sujeitos ou como a contabilidade de números de votos num processo eleitoral; a democracia é um modo de se existir no mundo, é um modo de vida é existir coletivamente.

Assim, sendo a democratização das escolas um processo, percebe-se que os níveis de evolução são diferentes. De um lado, existe um grande número de escolas que, no desen- 
volvimento deste processo de democratização, ainda se encontram orientadas por ações tradicionais, expondo os jovens a horários rígidos, a serem ouvintes passivos em sala de aula, copistas de lousa, entrincheirados em carteiras enfileiradas, reféns de livros didáti$\cos$, tarefeiros de lições repetitivas, muitas vezes, sem sentido e avaliados burocraticamente, de forma que este conjunto de condutas os insiram em um sistema macroeconômico que os manterão em um determinado lugar social. Por outro lado, há inúmeras escolas que se encontram bem desenvolvidas no que se refere ao processo de democratização e que promovem experiências de valorização da participação com voz e vez, com opinião, tomada de decisões, divisão de trabalho e de poder, ação e construção cooperativa e social do conhecimento muito especialmente pela pesquisa como base da Educação. Mediante essas últimas ações citadas, não se pode pensar que a denominação «escola democrática» tenha se tornado um adjetivo.

A escola analisada, objeto de pesquisa deste artigo, intitulou-se escola pesquisadora ao reinventar o conhecimento existente a partir das vivências e experiências dos alunos, fato este, que exigiu o enfrentamento e superação de diversas contradições. Entretanto, contradições parecem ser o combustível que alimentou o movimento das transformações na escola analisada. É possível afirmar que uma escola que integra de forma orgânica a educação pela investigação como base de ensino em seu projeto educativo transforma tais práticas em ações educativas, planejadas junto aos educandos; o educador atua como moderador, apoiando-se, basicamente, em discussões, em detrimento das instruções, ou seja, mais discussões e menos noções e conceitos prontos.

Entretanto, a preocupação em relação aos resultados objetivos dos alunos esteve presente nas representações de alguns educadores. Este pode ser um dos aspectos das contradições em relação às mudanças: tentar adequar o novo conhecimento às velhas estruturas. Apesar disso, foi possível observar, por intermédio das análises, que há uma melhora dos resultados na passagem dos bimestres no transcorrer do ano letivo. Embora existam tensões, conflitos e contradições, e não obstante hajam representações em um sentido que não se relaciona à uma escola com postura progressista, os alunos avançaram consoante as finalidades e objetivos da escola básica.

No cotejamento entre os Projetos [Político] Pedagógico dos anos de 2009 e 2014 percebe-se que mesmo na vigência do PP (2009), a comunidade escolar escolheu um posicionamento político de atuação na construção e distribuição do conhecimento. Neste momento de pensar estas conclusões, penso também na gênese política daquele bairro. Penso nos enfrentamentos daquelas pessoas frente às forças repressoras do Estado, so- 
bretudo a resistência daquelas mulheres que em algum número estiveram frente às armas e não se acovardaram ao direito à moradia. A gênese deste bairro não está descolada da ousadia das práticas pedagógicas daquela escola.

Os TCCs das meninas autoras e dos meninos autores, desde 2010, se anteciparam ao Decreto n⿳⺈ 54.452 (São Paulo, 2013), e tal fato não aconteceu por acaso, os fatos acontecem por desejos. Havia naquela comunidade educativa uma potência de desacomoda[ação], buscando dar sentido ao processo ensino e aprendizagem. O sentido que se refere aqui são aqueles para muito de direção, aqueles sentidos muito além dos fisiológicos. São mesmo os sentidos advindos das experiências vividas, aqueles insubstituíveis porque únicos de cada ser, ou ainda e mais contundentemente, os sentidos de se estabelecer sentido entre o que se aprende ao cotidiano para que se possa pensar [o verbo] e processualmente mudar a própria realidade.

Reforça-se aqui uma das proposições diretivas do presente estudo, de que as novas práticas e as criações eclodiram da necessidade de superação da realidade que estava posta, com intenções de promover o desenvolvimento dos educandos.

O livro intitulado Escola Pesquisadora: uma possibilidade de formação (Ferreira, 2013) se apresentou como parte de um projeto que reuniu dezoito artigos de professores da Emef Giuseppe Tavolaro, com a finalidade de refletir sobre a prática dos educadores. Neste contexto, esses educadores saíram do lugar de tutela em relação às políticas públicas cuja direção é sempre «de cima para baixo» e buscaram ousar na produção de conhecimento, tendo como ponto de partida o local de trabalho, bem como o dia a dia vivido. Mas não somente isso, foram estabelecidas a relação e a coerência entre o vivido, concebido, representado, ou seja, o professor que ensina também aprende. Desse modo, é possível que tenha havido a superação da representação dos professores de que somente os alunos é que estão em processo de aprendizagem.

As análises estatísticas dos resultados objetivos das avaliações realizadas pelos professores na escola pesquisada apontaram melhoria nos resultados. O Ideb, que vem sendo monitorado por órgão oficial, também revelou a mesma realidade. Entretanto, entendese que o fato da equipe gestora, dos professores e dos educandos terem uma longa trajetória de permanência na escola possa também ser um fundamental aspecto de contribuição no processo.

Encaminha-se para a finalização dessas considerações, de modo que é possível apontar um aspecto crucial do desenvolvimento da escola que realiza ações de pesquisa entre 
seus educandos e educadores: ela pode estar próxima, ou quiçá, frente a um momento de ruptura do status de educação tradicional, buscando outra síntese.

Indubitavelmente, há a preocupação por parte dos professores no que concerne ao cumprimento dos horários da escola, das aulas formais, do conteúdo a ser apresentado aos alunos, da qualidade das aulas, das notas, das avaliações externas, dos projetos, entre outras obrigações. Entretanto, é possível que alguns dos conflitos que surgiram no desenvolvimento dessas ações estejam requerendo outros tempos, outros fazeres, outros olhares, outros espaços. Manejá-los, readequá-los e conquistá-los permitindo a coexistência entre as diferentes épocas, bem como a utilização e a readequação dos espaços da escola, de modo que a educação nos modos majoritários do momento presente não seja a única forma de educação; e isso parece ser o próximo exercício entre educadores e educandos dessa escola que se auto intitulou como escola pesquisadora porque se reconheceu com uma nova identidade, num diferente e possível caminho de construção de conhecimento: uma escola pesquisadora.

\section{Lista de referências}

Bourdieu, P. (2010). As categorias do juízo professoral. Em Nogueira, M. A., \& A. Catani (Orgs.), Escritos de Educação (pp. 187-216). Petrópolis: Vozes.

Brasil. (1996). Lei nº 9394, de zo de dezembro de 1996. Estabelece as diretrizes e base da educação nacional. https://doi.org/10.5007/2175-7941.2017v34n1p1

Brasil. (2007). Portaria Normativa Interministerial n⿳ำ 17, de 24 de abril de 2007. Institui o Programa Mais Educação, que visa fomentar a educação integral de crianças, adolescentes e jovens, por meio do apoio a atividades sócio-educativas no contraturno escolar. Brasília, D. F.: Ministério da Educação. https://doi.org/10.11606/d. 48.2014.tde-17122014-103428

Brasil. (2011). Programa Mais Educação: Passo a passo. Brasília, D. F.: Ministério da Educação, Secretaria de Educação Básica. https://doi.org/10.14393/19834071.2012.17680

Canário, R. (2005). O que é Escola? Um «olhar» sociológico. Porto: Porto Editora.

Caria, A. de S. (2010). Projeto político-pedagógico: importância histórica de uma prática em crise. (Dissertação de Mestrado). Faculdade de Educação, Universidade de São Paulo, São Paulo, Brasil. https://doi.org/10.11606/d.48.2010.tde-26012011-135146

Demo, P. (2011). Educar pela Pesquisa. Campinas: Autores Associados.

Dewey, J. (2010). Arte como Experiência. São Paulo: Martins Fontes. 
Dewey, J. (2011). Experiência e Educação. Petrópolis: Vozes.

Escola Municipal de Ensino Fundamental Sebastiana da Silva. (2009). Projeto Pedagógico.

São Paulo: Escola Municipal de Ensino Fundamental Sebastiana da Silva. https:// doi.org/10.11606/d.106.2017.tde-10012017-143549

Escola Municipal de Ensino Fundamental Sebastiana da Silva. (2014). Projeto Político Pedagógico. São Paulo: Escola Municipal de Ensino Fundamental Sebastiana da Silva. https://doi.org/10.11606/d.106.2017.tde-10012017-143549

Ferreira, P. S. (Org.) (2013). Escola Pesquisadora: uma possibilidade de formação. Curitiba: CRV Editora. https://doi.org/10.24824/978858042854.4

Foucault, M. (1977). Vigiar e punir: nascimento da prisão. Petrópolis: Vozes.

Foucault, M. (2003). Microfísica do poder. Rio de Janeiro: Graal.

Fullan, M. (2009). O significado da mudança educacional. São Paulo: Artmed.

Hargreaves, A., Earl, L., \& Ryan, J. (2001). Educação para mudança: recriando a escola para adolescentes. São Paulo: Artmed.

Lefebvre, H. (1983). O materialismo Dialético. Moçambique: Acrópole LDA.

Lefebvre, H. (2006). La Presencia y La Ausencia. Contribución a la teoría de las representaciones. México, D. F.: FCE.

Rocha, J., \& Rozek, M. (2018). Quando o aprender na escola é (im)possibilidade. Revista Latinoamericana de Ciencias Sociales, Niñez y Juventud, 16(1), 361-373. https://doi.org/ $10.11600 / 1692715 \times .16122$

São Paulo. (2013). Decreto nº 54.452, de 10 de outubro de 2013. Institui na Secretaria Municipal de Educação, o Programa de Reorganização Curricular e Administrativa, Ampliação e Fortalecimento da Rede Municipal de Ensino-Mais Educação São Paulo de 2013. https:// doi.org/10.11606/d.48.2013.tde-11102013-111939

São Paulo. (2014). Programa Mais Educação São Paulo: subsídios para implantação. São Paulo: Secretaria Municipal de Educação, Diretoria de Orientação Técnica. https://doi.org/ 10.11606/t.48.2016.tde-20042016-103136

Stake, R. (1989). A arte da investigação com estudos de caso. Lisboa: Calouste Gulbenkian. Stenhouse, L. (2007). La investigación como base de la enseñanza. Madrid: Morata. 